\title{
Using monitoring technology in Cameroon
}

Gibson D'Cruz RN; EdD, MSc, BEd (Hons), BA, School Director of Teaching, Learning and Quality, School of Nursing \& Midwifery, Faculty of Health, University of East Anglia, UK; Honorary Senior Lecturer, University of Buea, Cameroon and Higher Institute of Applied Medical Sciences, Cameroon.

Kate Allen RN; MSc, PGCE(A), BSc, Lecturer (Critical Care)/Placements Officer, School of Nursing and Midwifery, Faculty of Health, University of East Anglia, UK; Honorary Lecturer, University of Buea, Cameroon and Higher Institute of Applied Medical Sciences, Cameroon.

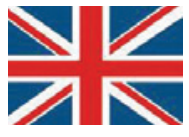

Key Words: Cameroon education * monitoring * nursing * patient safety technology *

E-mail: g.dcruz@uea.ac.uk

\section{ESPAÑOL}

Uso de tecnología de monitoreo en Camerún

\section{Palabras clave}

Camerún, educación, monitoreo, enfermería, seguridad del paciente, tecnología

Resumen

Este artículo examina algunos de los aspectos mas importantes relacionados con el uso de la tecnología en el cuidado de la salud, en particular el equipamiento de monitoreo en ámbitos de cuidado de la salud en Camerún, África Occidental.

Aunque la tecnología en el cuidado de la salud se utiliza ampliamente en varios países industrializados, este no es el caso en Camerún donde no esta disponible o si esta disponible no se utiliza.

Antes de iniciar su uso, se requiere realizar una evaluación de la tecnología para asegurar que el equipo que se pretende utilizar satisface una necesidad particular.

El problema clave a solucionar es la educación de los enfermeros y otro personal que usará la tecnología, ya que sin esta educación se compromete la seguridad de los pacientes.

En la formación de enfermería también deberá incluirse la consideración de otras alternativas para el monitoreo de los pacientes.

\section{SUMMARY}

- This paper examines some of the issues related to the introduction and use of healthcare technology, in particular monitoring equipment into the healthcare settings in Cameroon, West Africa.

- Although healthcare technology is used widely in many hospitals in industrialised countries, this is not the case in Cameroon where it is either not available extensively or where it is available, it is not used.

- Before it is introduced, a health technology assessment needs to be undertaken to ensure that the intended equipment is required to meet a particular need.

- The key issue that needs to be addressed is the education of the nurses and other personnel who will be using the technology as without this education, the safety of patients may be compromised.

- The education of nurses should also include a consideration of alternatives to technology to monitor patients.

\section{INTRODUCTION}

The growth of a country or region can be measured in a number of ways and one method that is commonly used is the role that technology plays in it. One of the features of advanced countries is the extent to which technology has played in its successful industrialisation and this is exemplified by the extent to which the manufacturing industry has used sophisticated technology to make a significant contribution to a country's Gross Domestic Product (King, 2007). Furthermore, in the industrialised West, science and technology are the tools that nations have used to improve their social and economic conditions and this could be extended to the heath of the nation. Barnard (1996) has suggested that a rapid upsurge in technological knowledge in recent years has led to a proliferation in the use of technology and this has generated changes, not only at societal level but also in nursing and healthcare.

The introduction and use of technology has been accompanied by a fascination with the role that technology plays in healthcare (Barnard, 1996). Morton et al., (2005) paints a vivid picture of intensive care units in hospitals in the West with monitors, ventilators and pumps and the sound of bleepers, buzzers and alarms. Whilst there are many aspects of this picture that are true and repeated in many intensive care units throughout the world, it is worth noting that technology is not just restricted to such units but can now be found in many wards and departments (Sheppard \& Wright, 2000), where the use of technological aids and devices is common and frequent. Between 2007 and 2008, we conducted some nursing curriculum development work in Anglophone Cameroon and as part of this work we visited many hospitals and health centres in South-West Cameron and noticed their distinct lack of technology. However, in the very same hospitals and health centres, there were scanners, infusions pumps and monitors present that were not in use. Perhaps the most striking incident was when we saw a large building that had an extensive amount of 'medical equipment' that had not been unpacked. Observations such as these have also been noted by the 
World Health Organization (WHO) which reported that about half the devices and equipment imported into African healthcare institutions are not being used and remains redundant (Howie et al., 2008).

When we asked our colleagues, who were accompanying us on these visits, for the reasons for the non-use of these devices, a number of issues were put forward. This paper will explore some of those reasons by examining the need for and usage of healthcare technology in Cameroon. In particular, we will discuss the range of healthcare technology that is currently available before examining the issues related to its use, with particular emphasis on patient safety. We will conclude by recommending that education of the users of healthcare technology should occur if this technology is to be used effectively and efficiently. Although our observations and comments relate to Cameroon, they may be applicable to many other countries in sub-Saharan Africa.

\section{CAMEROON}

Cameroon is an independent country located in the tropical region of West Africa. $50 \%$ of the population live on less than US $\$ 2.00$ per day although the level of poverty has fallen to $40 \%$ in the period between 1996 and 2001 (Department for International Development, 2006). Life expectancy at birth is 56 years and there is a high infant mortality rate (63 deaths per 1,000 live births). Although healthcare services are provided by government, private or mission-funded hospitals, many people do not have access to healthcare and this is due to either poverty, rural locations with an inadequate infrastructure, bad roads and/or lack of transport. In addition to issues of access, Cameroonian healthcare institutions do not have sufficient human and material resources (Fongwa, 2002). Total Government spending on healthcare reduced from $8 \%$ in $1980-1982$ to only $1 \%$ in $1990-$ 1991 (Fongwa, 2002) and the latest figures indicate that it is now at $11 \%(\mathrm{WHO}, 2006)$, compared with $21 \%$ in the United States of America (USA) and $16 \%$ in the United Kingdom (UK). In terms of human resources, in Cameroon there are two physicians per 10,000 population compared with 26 and 23 in USA and UK respectively. The Cameroonian level of physician density means that nurses are at the forefront of healthcare and there is a great deal of an onus placed on them to make decisions related to the care and management of a patient.

Literature on the use of technology in healthcare in Cameroon in particular and sub-Saharan Africa as a whole is scarce although some parallels can be drawn from the literature on information technology. Writing specifically on the use of computers in Francophone West Africa, Akindes (1998, p. 30) uses the term 'scientific isolation' to describe the region- one that is slow in adopting computer technology. This view is echoed by Oguariri and Kabara (2008) who describe the current state of critical care nursing in Nigeria and note a lack of sufficient technology devices in the intensive care units there.

\section{TYPES OF TECHNOLOGY}

Healthcare technology can be broadly divided into four categories, with each serving a specific function. The first category is the equipment or devices that can be used to maintain or sustain the life of an individual (Woodrow, 2000). For example, ventilation of the lungs can be achieved mechanically by the use of a ventilator. A patient's renal function can be maintained through the use of a haemodialysis machine, which acts as an artificial kidney and the functions of the heart during cardiac surgery can be undertaken by a heart/lung bypass machine. All these have been influential in maintaining life in a period of critical illness, which in previous years would have almost certainly resulted in death. The second category of technology can be used to maintain patient safety. For example, if a patient requires a drug whose dosage needs to be carefully titrated, an infusion pump can be used to accurately deliver the precise amount (Murdoch \& Cameron, 2008). Similarly, a pressure-relieving mattress can be used to prevent the occurrence of a pressure sore in a patient whose mobility is severely restricted and whose risk of developing a pressure sore is high. The third category of technology is the equipment and devices that are used for record keeping. Computers and information technology are now used widely to aid record keeping and the transfer of information, so it is very common to see a patient's care plan being documented and stored electronically.

The final category of technology is that which can enable a patient's condition to be monitored and any deviations from the norm detected. For example, pulse oximetry can accurately measure arterial saturation of functional haemoglobin in a patient (Allen, 2004), whilst a cardiac monitor can record electrical activity in the heart thus reflecting cardiac function. It is this category of technology that this paper will focus on, as it is this area that raises most questions about the role and value of technology. When considering the role technology can play in the monitoring of patients in healthcare settings in Cameroon, there are a number of factors that must be considered and the next sections of this paper will explore these, with the use of specific examples of monitoring devices to highlight points. When further considering the focus of this paper, it is important to acknowledge that it excludes the point that technology has the potential to dehumanise and depersonalise patients and nursing care, resulting in a reduction in the patient's individuality and dignity as a human being, (Barnard \& Sandelowski, 2001). This fundamental issue has led to extensive debate in the West regarding the appropriateness and use of technology (Carnevale, 1991; Wilkinson, 1992; Benner, 2001; Almerud et al., 2008).

\section{Is technology really necessary?}

The first issue relating to the role of 'monitoring' technology is to question whether it is actually needed and if value for money is gained by purchasing it. Disease patterns and level of patient acuity can vary from country to country, region to region and hospital to hospital. In Cameroon, $49 \%$ of deaths are due to HIVIAIDS, lower respiratory infections, malaria and diarrhoeal diseases (WHO, 2006). Monitoring technology of an advanced nature, for example, Doppler probes for the measurement of cardiac output, may not always be as necessary for these groups of patients as they may have other greater needs. Consequently it would seem inappropriate to purchase a piece of expensive technology if it is not to be used in an efficient manner. If, for example, a health centre acts as a triage centre for patients in a rural setting, it would seem churlish to purchase an expensive cardiac monitor when an accurate and comprehensive assessment of the patient could be undertaken using the 'basic' devices of a thermometer, sphygmomanometer and the perceptual skills of the nurse. Similarly, a patient's oxygenation level can be assessed, albeit not as precisely, by a visual examination of a patient's buccal mucosa or finger tips, thus negating the need for pulse oximetry. The assessment could be effectively conducted using a recognised and familiar framework that would facilitate a systematic approach to ascertaining the patient's health status. The value of a recognised framework will be discussed in more detail later in this paper. Therefore, in most instances, the patient's physical status can be accurately monitored and established through the use of the assessment skills of a nurse and if a monitoring device is available, it can be used to verify the nurse's assessment of a patient rather than actually adding to the assessment.

\section{The need for safety}

As most monitoring devices require a steady stream of electricity in order to function, it would seem obvious to ensure that there is a sufficient supply of electricity in a healthcare setting. During our visits to Cameroon, we experienced power cuts and failures on a frequent basis and this is a 'fact-of-life' for many Cameroonians. 
Most monitoring devices have an alarm that is triggered off when the electricity supply is diminished and the sound of this alarm can be source of anxiety for many patients and staff if they are not aware of the reasons for it. Although most devices may be operated on a battery, this would not be a viable option as batteries can be expensive, especially if they have to be imported and then transported to a hospital. In addition to the availability of electricity, there is a need to ensure that the electricity supplied is at the compatible voltage to that of the device. Too high a voltage may result in combustion of the device whilst too low a voltage may mean that the device would not function effectively.

All technological devices need to be maintained and checked to ensure that they are in a safe working order. Also included in this is the need to calibrate some devices such as arterial pressure monitors. This checking and maintenance of equipment requires appropriate personnel as it is often beyond the scope of a nurse or a physician to ensure that a device is in a safe working order prior to and during its use. Many hospitals in the UK have medical engineering departments whose sole function is to ensure that devices are in a safe working order (Greenall, 2000). At present, there are approximately 200 critical care technologists who work within critical care units in the UK and these professionals have advanced knowledge of human physiology and the technology involved in the delivery of critical care to patients. Their presence enables the nursing and medical staff to concentrate on their own aspects of patient care, and not upon the technology. Whether this level of service may be available in many hospitals in Cameroon is debatable as the personnel need to be trained and educated before they can undertake this role (Oguariri \& Kabara, 2008).

In addition, there is a need for a government agency whose role is to ensure that all devices used in healthcare institutions are safe and are fit for the purpose it was designed for. For example, in the UK, the Medicines and Healthcare Products Regulatory Agency is a government agency that plays a key role in this and occasionally issues 'hazard warning' and 'safety' notices (Greenall, 2000) to practitioners if the Agency becomes aware of certain malfunctions of a device. Other countries, for example Malaysia, are currently working on developing regulations in the use of medical devices, with standards also being developed to ensure safety (Thangavelu et al., 2008). Again, whether the central governments of Cameroon have this type of a service is difficult to establish although Riha (2008) has suggested that this level of technical skills and expertise is not available in Cameroon.

A further point regarding the maintenance of technological devices is the role that manufacturers play in ensuring its safe use. In the West, companies are able to provide long-term warranties for their products, as they know that they can respond swiftly to a need for maintenance of a device or if a replacement part or device is needed. Whether Western companies will extend this level of service to healthcare institutions in Cameroon is highly debateable because of the distances and difficulties involved in travelling to institutions to maintain and/or service these devices.

The final major point about the use of technological devices and undoubtedly the most important is that appropriate care actions should be taken if an abnormality is found in a person's physiological functioning as it would be unethical and an inappropriate use of resources if no action is taken. Within this area, consideration needs to be given to whether a certain medication or therapy is readily available. For example, if pulse oximetry detects that patient's haemoglobin saturation levels is $90 \%$ (the normal and accepted value in a healthy individual is $95 \%$ and above (Hinds \& Watson, 1996), is oxygen available to be administered to the patient? As stated in the introductory section of this paper, healthcare institutions in Cameroon do not always have the necessary material resources that are generally available in the more affluent countries.

\section{The need for education}

Before a nurse or a doctor uses a technological device it is important that they are trained and educated in it. This education should include the recognition of instances when a certain device is appropriate for a particular patient and also in its safe use. For example, a nurse needs to differentiate between those occasions when continuous monitoring of a patient's cardiac function is needed and when a 12-lead recording of the electrical conduction of the heart is more suitable. Similarly, there are clinical circumstances when an estimation of glucose levels in a patient can be undertaken by assessing a patient's urine and there are those when a more precise serum glucose level is required, and for the latter a glucometer is needed. Distinguishing between these types of scenarios can not only ensure that devices are used at the right time and for the right patient but it can also help to reduce anxiety levels in patients who may become alarmed when they see a nurse or a doctor using an unfamiliar technological device as part of their assessment.

In addition, practitioners need to be aware of appropriate use of a certain piece of equipment. Leads must be placed at specific locations on a patient's chest if an accurate recording of their electrocardiogram (ECG) is to be obtained. Fingers need to be well perfused and warm if an accurate haemoglobin saturation level is to be obtained (Jevon \& Ewens 2002). If the devices are not used in the correct manner, they may give inaccurate readings leading to inappropriate treatments (Urden et al., 2004) as well as a general mistrust of equipment. On the other hand, practitioners need to be educated in how to interpret the results that are being obtained through the use of a technological device. A nurse needs to be able to distinguish between a normal ECG, with the usual P, QRS, T waves being present, from an ECG with the $P$ wave missing. On occasions, the deviations from the normal values and range for a certain physiological parameter can only be discerned through an experienced eye and this requires constant exposure to a technological device if this experiential knowledge is to be gained. But to start with, all staff who will be or are likely to use technological devices need to be taught basic physiological principles and detection and assessment of variations.

\section{RECOMMENDATIONS}

There are two main points that can be surmised from the above discussion. The first is that technological aids should be introduced with a strategic intention in mind. The need for a certain device should be ascertained by examining the epidemiological, economic and personnel factors. The strategy that is developed needs to be dynamic in responding to changes in disease patterns, which can alter, as was noted by Trowell and Burkitt (1981), who cite the growing incidence of 'Western diseases' such as heart disease, diabetes and dental caries in sub-Saharan Africa with the adoption of Western lifestyles. The strategy also needs to take into consideration the cost of equipment, as it is expensive. This was borne out by Houngbo et al. (2008) who report that each year US $\$ 10.6$ million, which is $20 \%$ of the total health budget of Benin, West Africa is being spent on the procurement of medical devices and equipment. If all the evidence indicates that a specific technological device would be of value for a healthcare organisation, then there is clear justification for spending the available resources. However, it is worth noting that very few devices used in intensive and critical care settings have been subject to rigorous evaluation prior to their use (Scales \& Laupacis, 2007) A health technology assessment, which is the process of evaluating the effectiveness, costs, and broader health system and societal impacts of a health technology (Velasco-Garrido \& Busse, 2005) needs to be conducted and this should also include issues of costeffectiveness and affordability as well as the diagnostic accuracy of the technology.

Simultaneous to, or more importantly, prior to the introduction of the technology, the users of any proposed equipment should be 
educated and trained in using it safely, effectively and competently. As far back as 1991, the need for education and training in the use of haemodynamic devices was recognised as being crucial (Calvin \& Holt, 1991) and this need for education is just as important now as it was then. If this education is not provided before and continued after its introduction, the technological device can at best be a redundant piece of equipment and at worst be a danger to a patient's life. As Ashworth (1990, p. 151) identified, "technology is only as good as those who use it."

\section{REFLECTIONS}

During the course of our visits to healthcare institutions and schools of nursing, we conducted several sessions on 'recognising and assessing a critically-ill patient'. This assessment was within the ABCDE framework (Smith et al., 2002) and the overwhelming response from the attendees was that these sessions were particularly useful as they did not advocate the use of any form of technology but instead relied on a nurse's knowledge and skill to undertake a comprehensive assessment. The attendees also felt that the framework on its own, without the use of any monitoring devices would be more relevant for nursing in Cameroon due to the lack of suitable equipment. Although we were not suggesting to the attendees and participants that technology should not be used in Cameroon, we were aware of the need to contextualise our teaching to fit the reality of healthcare in Cameroon. It was this that made us realise that we have come to view technology as a 'given' in our practice but for those who provide care in different countries, this may not be the case. We have also come to realise that the skills that many nurses have in assessing and recognising ill-health in a patient may become a dying art through the heavy reliance on technology and we are now encouraging the use of our 'five senses' in the assessment of patients. The ABCDE framework has now become a by-word for us and for the nurses we have taught in Cameron and also in our present roles.

A final point that is worth considering is a philosophical one about the role of technology in care. As stated in the introduction, debates have been taken place in the West that technology has the potential to dehumanise patients (Benner, 2001) and that lesser-qualified people or robots (Woodrow \& Roe, 2000, p. 5) can be employed in place of nurse. Advancement of knowledge and technological developments actually add to, not decrease the responsibilities of nurses in Cameroon who are required to manage and monitor the effects of interventions, as they very often need to be able to act and respond independently to the data obtained.

\section{CONCLUSION}

Cameroonian healthcare institutions need to be mindful not to uncritically accept the use of technology in healthcare or they may experience the same criticisms which first emerged in the 1960s when there was a growing body of criticism directed at the transfer of technologies from the West to newly independent developing countries (Hubley, 1988). As Pearson (1993) has suggested technology has saved many lives and improved the quality of life for many more. However, there needs to be a careful deliberation of the role that technology can play before it is introduced into healthcare settings and a need to ensure that the infra-structure, support networks and education of the users is in place before it is used.

\section{REFERENCES}

Akindes SA (1998). "Go slow" or crash: education, society, and new technologies in Francophone West Africa. Bulletin of Science, Technology \& Society 18 (1), 30-37.

Allen K (2004). Principles and limitations of pulse oximetry in patient monitoring. Nursing Times 100 (41), 34-37.
Almerud S, Alapack RJ, Fridlund B, Ekebergh M (2008). Beleaguered by technology: care in technologically intense environments. Nursing Philosophy 9 (1), 55-61.

Ashworth P (1990). High technology and humanity for intensive care. Intensive Care Nursing 6 (3), 150-160.

Barnard A (1996). Technology and nursing: an anatomy of definition. International Journal of Nursing Studies 33 (4), 433-441.

Barnard A, Sandelowski M (2001). Technology and humane nursing care: (ir)reconcilable or invented difference? Journal of Advanced Nursing 34 (3), 367-375.

Benner P (2001). Death as a human passage: compassionate care for persons dying in critical care units. American Journal of Critical Care 10 (5), 355-359.

Calvin JE, Holt AA (1991). Guidelines for medical technology in critical care. Canadian Medical Association Journal 144 (12), 1617-1622.

Carnevale F (1991). High technology and humanity in intensive care - finding a balance. Intensive Care Nursing 7 (1), 23-27.

Department for International Development (2006). Country Profiles - Cameroon. [Online] Available at: http://www.dfid.gov.uk/ countries/africa/cameroon.asp [Accessed 09 January 2009].

Fongwa MN (2002). International Health Care Perspectives: The Cameroon Example; Journal of Transcultural Nursing 13 (4), 325-330.

Greenall M (2000). Principles involved in the management and use of equipment. In Davey A, Ince CS (editors), Fundamentals of Operating Department Practice. London: Greenwich Medical.

Hinds CJ, Watson D (1996). Intensive Care, A Concise Textbook, 2nd Edition. London: W.B. Saunders.

Houngbo PT, Medenou D, Bunders J, van der Wilt G J, Ruitenberg $\mathrm{J}$ (2008). Policy and Management of Medical Devices for the Public Health Care Sector in Benin. Paper presented at Appropriate Healthcare Technologies for Developing Countries Conference, London, United Kingdom. [Online] Available at: http://conferences.theiet.org/aht/pdfs/003-Bunders.pdf [Accessed 03 December 2008].

Howie S, Hill S, Peel D, Sanneh M, Njie M, Hill P, Mulholland K, Adegbola R (2008). Beyond good intentions: lessons on equipment donation from an African hospital. Bulletin of the World Health Organisation 86 (1), 52-56.

Hubley J (1988). Health education in developing countries - the need for an appropriate technology. Health Education Research Theory and Practice 3 (4), 387-392.

Jevon P, Ewens B (2002). Monitoring the Critically III Patient. Oxford: Blackwell Science.

King EB (2007). Making sense of the failure of rapid industrialisation in the Philippines; Technology in Society 29 (3), 295-306.

Morton PG, Fonatine D, Hudak CM, Gallo BM (2005). Critical Care Nursing- A Holistic Approach, 8th edition. Philadelphia: Lippincott, Williams \& Wilkins.

Murdoch LJ, Cameron VL (2008). Smart infusion technology: a minimum safety standard for intensive care? British Journal of Nursing 17 (10), 630-636.

Oguariri O, Kabara H (2008). Perspectives on critical care nursing: Nigeria. Connect: The World of Critical Care Nursing 6 (1), 13-16.

Pearson A (1993). Nursing, technology and the human Condition (editorial). Journal of Advanced Nursing 18 (2), 165-167.

Riha J (2008). Development of the National Healthcare Technology Policy for Cameroon. Paper presented at Appropriate Healthcare Technologies for Developing Countries Conference, London, United Kingdom. [Online] Available at: http://conferences.theiet. org/aht/pdfs/002-Riha.pdf [Accessed 03 December 2008]. 
Scales DC, Laupacis A (2007). Health technology assessment in critical care. Intensive Care Medicine 33 (12), 2183-2191.

Sheppard M, Wright M (2000). Principles and Practice of High Dependency Nursing. London: Bailliere Tindall.

Smith GB, Osgood VM, Crane S (2002). ALERT- a multiprofessional training course in the care of the acutely ill adult patient. Resuscitation 52 (3), 281-286.

Thangavelu SD, Pillay MS, Yunus J, Ifeachor E (2008). Towards Implementation of International Standards in Medical Devices Regulation in Malaysia. Paper presented at Appropriate Healthcare Technologies for Developing Countries Conference, London, United Kingdom. [Online] Available at: http:// conferences.theiet.org/aht/pdfs/005-Thangavelu.pdf [Accessed 03 December 2008].

Trowell HC, Burkitt DP (1981). Western Diseases - their Emergence and Prevention. London: Edward Arnold.
Urden L, Stacy K, Lough M (2004). Priorities in Critical Care Nursing, 4th edition. St Louis: Mosby.

Velasco-Garrido M, Busse R (2005). Health technology assessment: an introduction to objectives, role of evidence, and structure in Europe. Brussels: European Centre for Health Policy, World Health Organization.

World Health Organization (2006). Mortality Country Factsheet 2006. WHO: World Health Statistics. [Online] Available at: http://www.who.int/whosis/database/core/core_select_process. cfm?country=cmr\&indicators=nha [Accessed 23 March 2009].

Wilkinson $P$ (1992). The influence of high technology care on patients, their relatives and nurses. Intensive and Critical Care Nursing 8 (3), 194-198.

Woodrow P, Roe A (2000). Intensive care nursing: a framework for practice. London: Routledge. 